BJECTIVE DIAGNOSIS OF OTITIS MEDIA (OM) IN EARLY 810 CBJECTVE DIACNaris OF PA MCMillan, PA Shurin, CE Johnson, VA Turczyk, DE Murde11, Case Western Reserve University, Cleveland Metropolitan General Hospital, Department of Pediatrics, Cleveland, Ohio.

Young infants with $\mathrm{OM}$ are at high risk for the development of prolonged middle ear effusion (MEE) and recurrent OM. Objective, non-invasive diagnostic methods are needed for this age group. We determined the diagnostic efficacy of ipsilateral acoustic reflexes (IAR) detected with a $1000 \mathrm{~Hz}$ stimulus and susceptance (B) tympanograms $(660 \mathrm{~Hz})$ (NEJM $296: 412,1977)$. Seventy-two infants $<4 \mathrm{~m}$. of age who presented at we1l child and illness visits were studied prospectively. Quantitative measures examined were: 1) peak $B, 2$ ) mean $B$ between +300 and $-400 \mathrm{~mm} \mathrm{H}_{2}$ ) and 3) IAR threshold in decibels ( $\mathrm{dbHL}$ ). These measures were compared to independent pneumatic otoscopic findings. Substantial agreement was achieved between independent otoscopists (Kappa $=.73$ ). Diagnoses were confirmed by tympanocentesis when clinically indicated.

Results: peak B mean $B$ IAR Criterion for Absence of MEE $\frac{>0.2 \mathrm{mmho}}{91 \%} \frac{>0 \mathrm{mmho}}{84 \%}<100 \mathrm{dbHL}$ $\begin{array}{lllll}\text { SENSITIVITY ( } 56 \text { ears with MEE) } & 91 \% & 84 \% & 86 \% \\ \text { SPECIFICITY (76 ears no MEE) } & 86 \% & 86 \% & 89 \%\end{array}$ SPECIFICITY (76 ears no MEE) $86 \%$
$86 \%$ mmo in 47 infants $<2 \mathrm{~m}$. and 0.68 mmo in 21 infants $2 \mathrm{~m}$. to $4 \mathrm{~m}$. $(p<.005)$. Conclusions: Infants less than $4 \mathrm{~m}$. of age: 1) Tympanogram peak susceptance and ipsilateral acoustic reflexes are accurate, objective, quantitative diagnostic methods. 2) Developmental changes in peak susceptance may have obsured the value of tympanograms in previous studies.

\section{A CONSULTATIVE PRACTICE IN PEDIATRIC INFECTIOUS}

811 DISEASES. Anthony Minnefor, James M. 01eske (Spon. by Franki in (. Behrle). St. Joseph's Hospital and Medical Center. Department of Pediatrics. Paterson, New Jersey. Little if any information is available concerning the spectrum of $i l 1$ ness encountered during the day to day practice of pediatric infectious diseases. Poretz (J. Infect. Dis. 147:417-427, 1983) presented his experience with inpatient and outpatient consultations for a primarily adult population seen during part of 1982. We reviewed patient records for 1408 infants, children, and adolescents seen by one of us in inpatient infectious disease consultation during the period $01 / 01 / 81$ to 12/01/83.

Patients ranged in age from neonates through 21 years. Consultations were requested by pediatricians, family practitioners, internists, medical and surgical subspecialists and seen at one of nine institutions in northern New Jersey. Consultations were classified according to organ system involved, age and disease category. Several striking differences emerged when compared to Poretz's experience with adults. These include less post general surgical and gynecologic infections; bone and joint infections are problems in all age groups. In our study, neonates (by are problems in all age groups. In our study, neonates (by definition) dermatologic, gastrointestinal and respiratory tract infections were more prominent. This study has implications for
undergraduate, graduate and post graduate education in infectious diseases. This experience has been used effectively to develop teaching sessions at involved institutions. Data on telephone inquiries from physicians will also be presented.

\section{RESIDENTS' KNOWLEOGE OF BEHAVIORAL}

813 PEOLATRICS S. Phillips, S. B. Friedman, B. H. Zebal, Dept Performance on Psych, Univ Md Sch Med, Baltimore 30-item addendum assessing behavioral knowledge was compared for four groups of programs, three of which were participating in a separate, formal evaluation of behavioral training. The groups were: 10 schools funded for mandatory behavioral training, 6 not funded but providing mandatory training, 4 comparison programs not requiring training but participating in the formal evaluation, and all other (221) schools whose residents took the exam. Three measures were calculated for each of 4,433 residents: $\%$ correct on "organic" items (exam items not related to behavior); $\%$ correct on the "behavioral" items in the addendum; and a behavior); $\%$ correct on the "behavioral" items in the addendum; and a ratio score (Behavior score/Organic score). For all three PL years,
Organic and Behavioral scores were only moderately correlated $(r: .16-$ $.52)$. No significant differences were found in Organic performance between the four groups. In contrast, Behavioral and Ratio scores yielded significant (and similar) effects: Ratio scores were higher for Funded residents in the PL-1 year than for any other PL-1 group. For PL-2s, Funded, Not Funded, and Comparison residents performed better than the All Other group. By the third year, Funded residents performed better than those in the All Other group (Not Funded and Comparison better than those in the All Other group (Not Funded and Comparison
scores fell in between). These data suggest that: (1) behavioral scores fell in between). These data suggest that: (1) behavioral
knowledge is only moderately related to organic knowledge; (2) requiring behavioral training does not affect the level of organic knowledge; (3) Funded programs attract residents more knowledgeable about behavior who, during their training, maintain greater knowledge than residents not participating in a formal evaluation of behavioral training.
PLACE OF BIRTH FOR VERY LOW BIRTHWEIGHT VLBW (1500

814 GRAMS) INFANTS: DOES IT MATTZR? Ton se Raju, Ann Winegar, Steve Miller, Paul Peterson, Nilliam Spe1lacy, Dharmapuri vidyasagar, Department of Pediatrics and Obstetrics, Unlversity of Illinois Medical Center, Chicago, Illinois.

To evaluate the effect of place of birth on the morbidity and To evaluate the effect of place of birth on the morbidity and
mortality of VLBW infants, we analyzed data ( 320 variables from each mother-infant pair collected prospectively) from $25,120 \mathrm{in-}$ fants born in our Perinatal network of 3 Level III (L. III) and 9 Level II (L. II) hospitals over an 18 month period. 397 VLBW and 2145 low birth weight infants $(<2500 \mathrm{gm}$, LBW) formed a subset. L. IIX hospitals have pediatric and $O B$ residencies, and perinatal fellowship programmes: only $3 / 9$ L II hospitals have pediatric and $\mathrm{OB}$ residencies. Results. L III centers cared for a greater fraction of mothers on public aid $(45 \%$ Vs $29 \%, \mathrm{P}<0.0001)$, and teen-
age mothers ( $<1.6$ years, $5 \%$ Vs $2 \%, \mathrm{P}<0.001)$. Total perinatal and neonatal mortality rates (PMR, NMR) were higher in L III than in L II ( 16.3 and 106 Vs 10.1 and 4.7 ) which was mainly due to a $150 \%$ and $268 \%$ higher VLBW and LBW rates. However, for VLBW infants born in L III, 5 minute Apgar score distribution was significantly superior and PMR was better than for those born in L II. (Table) Outcome of $<1500 \mathrm{gm}$ infants: (Table) $\begin{array}{llll}* \mathrm{P}=<0.001 \mathrm{LBW} & \text { VLBW } & \text { Fetal \% Neo. PMR Apgar 0-3 Apgar 0-3 } \\ * * \mathrm{P}=<0.05 \text { Rate } & \text { Rate Death Death } & \text { at I min. at } 5 \text { min. }\end{array}$ Leve1 II $7.1 \% * \quad 0.91 \% * 24.3 \% \quad 36 \% * * \quad 485 * * \quad 46 \% * * \quad 28 \% * *$ \begin{tabular}{llllllll} 
Level III $10.5 \% *$ & $2.5 \% *$ & $11.6 \%$ & $31 \%$ & 382 & $40 \%$ & $16 \%$ \\
\hline These data indicate that for the high risk vLBW infants, availa-
\end{tabular} bility of supportive services is cruial for good outcome; fetal transfer may be better than high risk neonatal transfer.
PRENATAL ANTECEDENTS OF CHILD MALTREATMENT, John M.

812 Pascoe (Spon. by Marshall Klaus). College of Human Medicine, Department of Pediatrics/Hunan Development, Michigan State University, East Lansing, MI.

Child maltreatment remains a major problem in the United States, the etiology of which is complicated by contributions from biological and social factors. To further clarify the antecedents of child maltreatment, 100 consecutive mothers seen in an urban community hospital obstetric clinic for indigent in an urban conmunity hosp studied to determine prenatal and perinatal biological and social factors related to a subsequent perinatal biological and social factors related to a subsequent
report to a department of social services (DSS) for suspected child maltreatment. Fourteen mothers from this study group were referred to DSS before their child was 24 months old. Of the 24 variables assessed, 7 were associated with referral to DSS. 1) Maternal smoking during pregnancy, 2) C-section, 3) NICU admission, and prenatal maternal feelings of: 4) inadequate daily task-sharing among family members, 5) dissatisfaction with visits from extended family, 6) dissatisfaction with male support, 7 ) dissatisfaction with other support figures. An index was constructed with each of these factors scored " 1 " when present and " 0 " when absent. Using this index 86\% of mothers referred to DSS vs $43 \%$ of mothers not referred to DSS had scores $>3(p<.01)$

These data support the findings of previous work on the antecedents of child maltreatment. They emphasize the relationship between prenatal maternal dissatisfaction with support networks, perinatal biological difficulties and subsequent parent-child interaction problems.

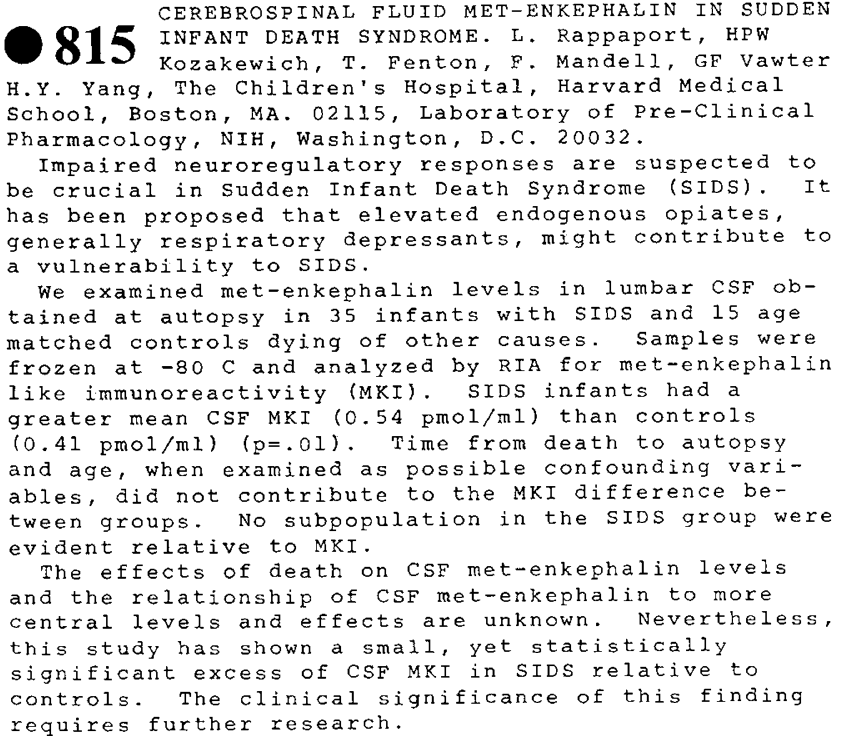

FROSPINAL FLUID MET-ENKEPHALIN IN SUDDEN INFANT DEATH SYNDROME. L. Rappaport, HPW ( H.Y. Yang, Pharmacology, NIH, washington, D.C. 20032.

Impaired neuroregulatory responses are suspected to has crucial in sudden Infant Death Synarome (SIDS). generally respiratory depressants, might contribute to

We examined met-en 15 age matched controls aying of other causes. Samples were frozen at -80 Cind analyzed by RIA for met-enkephalin (0.4l mean CSF MKI (0.54 pmol/ml) than controls and age, when examined as possible confounding variables, did not contribute to the MKI difference beevident relative to MKI.

The effects of death on CSF met-enkephalin levels and the relationship of CSF met-enkephalin to more this stuay has shown a small, yet statistically controls. The clinical significance of this finding requires further research. 